IgA and IgM were normal, and IgE was raised at $550 \mathrm{kU} / 1$. Autoantibodies were negative. $\mathrm{C} 3$ and $\mathrm{C} 4$ were 1.5 and $0.19 \mathrm{~g} / \mathrm{l}$. She was treated with fluid restriction, vitamin $\mathrm{K}$, cimetidine, albumin and, three days after admission, prednisolone $1 \mathrm{mg} / \mathrm{kg} / 24$ hours. Four days after admission grade III hepatic encephalopathy developed and prothrombin time lengthened to 70 seconds. Because of further deterioration, orthotopic liver transplantation was performed 24 hours later when prothrombin time was 120 seconds. The excised liver was shrunken with evidence of submassive necrosis. On histology there was widespread inflammation comprised of lymphocytes, pigmented macrophages, neutrophils, and fewer plasma cells (fig 1B). The child died of infectious complications three months after transplant.

In both cases hepatitis $\mathrm{A}$ and $\mathrm{B}$, cytomegalovirus, Epstein-Barr, measles, and leptospira infections were excluded; $\alpha_{1}$ antitrypsin phenotype and caeruloplasmin, plasma and urine copper, serum potassium, calcium, phosphate, glucose, cholesterol, creatinine, and urea concentrations, and urinalysis were normal.

\section{Discussion}

The diagnosis of liver injury induced by drugs rests on the exclusion of other aetiological factors. In the two children described no other cause of liver damage or drug exposure could be identified.

Hepatic side effects of carbamazepine are very rare. Among them, changes in results of liver function tests, jaundice, and granulomatous or cholestatic hepatitis are the most common. ${ }^{3}$ In a study of children, a clinically insignificant rise in results of liver function tests was found in $6 \%$ of 220 patients. ${ }^{4}$ We have identified only three reported cases of fatal acute liver failure directly attributable to carbamazepine, one being a child. ${ }^{1}$ Recently four children with fatal fulminant hepatitis while on carbamazepine were reported. ${ }^{2}$ All were taking several drugs, with three receiving other potentially hepatotoxic drugs, such as phenytoin and pri- midone. The mechanism of liver injury in carbamazepine hepatitis remains poorly understood, although it is presumed to be an idiosyncratic hypersensitivity, ${ }^{5}$ possibly deriving from genetically determined inability to inactivate toxic metabolites. ${ }^{6}$ Consistent with reports from other authors, we found that clinical presentation and laboratory tests in our two patients suggest an immunoallergic mechanism. Thus both had onset of symptoms four weeks after starting treatment, fever, rash, arthralgia, and raised IgE with carbamazepine concentrations within the therapeutic range. In addition, case 1 had a heavy plasma cell infiltrate found on histology, decreased complement concentration with increased IgG and $\operatorname{IgM}$, and her recovery has been aided by the administration of steroids. In case 2 these features were absent and no response to steroid was observed, possibly suggesting another mode of hepatocyte injury.

Liver function tests performed routinely in the first weeks of carbamazepine treatment, and in the presence of other idiosyncratic reactions to the drug, may help to detect patients at risk of developing this rare complication.

We thank Dr TK Hanid and Dr DM Cook for referring the patients. NH is a Bristish Council Research Fellow, GMV is supported by the M McGough Foundation Against Liver Disease in Children.

1 Zucker P, Daum F, Cohen MI. Fatal carbamazepine hepatitis. F Pediatr 1977;91:667-8.

2 Smith DW, Cullity GJ, Siberstein EP. Fatal hepatic necrosis associated with multiple anticonvulsant therapy. Aust $N Z \mathcal{F}$

Med 1988;18:575-81.
3 Horowitz S, Patwardhan R, Marcus E. Hepatotoxic reactions associated with carbamazepine therapy. Epilepsia 1988; 29:149-54.

4 Pellock JM. Carbamazepine side effects in children and adults. Epilepsia 1987;28(suppl 3):S64-70.

5 Stricker BHC. Hepatic injury by drugs and environmental toxins. In: Arias IM, Frenkel M, Wilson JHP, eds. The liver annual/6. Amsterdam: Elsevier, 1987:538-92.

6 Shear NH, Spielberg SP. Anticonvulsant hypersensitivity syndrome. In vitro assessment of risk. 7 Clin Invest 1988;82:1826-32.

\section{Addendum}

Since this paper was accepted we have admitted and successfully transplanted a 3 year old child who had fulminant hepatic failure due to carbamazepine toxicity.

\title{
Contractural arachnodactyly with mitral regurgitation and iridodonesis
}

\author{
I C Huggon, J P Burke, J F Talbot
}

Paediatric Unit,

\section{Northern General}

Hospital

I C Huggon

Department of Ophthalmology, Royal Hallamshire Hospital, Sheffield

J P Burke

J F Talbot

Correspondence to: Correspondence to:
Mr J P Burke, Department of Ophthalmology, Royal Hallamshire Hospital,
Sheffield S10 2JF.

Accepted 9 October 1989

\begin{abstract}
An infant girl with arachnodactyly, spontaneously resolving contractures, dolichostenomelia, iridodonesis, and mitral and tricuspid incompetence died in cardiac failure. We confirm that congenital contractural arachnodactyly may exhibit serious cardiovascular and ophthalmic complications like Marfan's syndrome. The presence of iridodonesis further obscures the differentation between classical Marfan's syndrome and congenital contractural arachnodactyly.
\end{abstract}

Beals and Hecht described an autosomal dominant syndrome of congenital contractural arachnodactyly distinct from classical Marfan's syndrome. ${ }^{1}$ It is characterised by multiple contractures at birth that resolve spontaneously (in 94\%), dolichostenomelia, arachnodactyly (in $85 \%$ ), abnormalities of the external ears (in $65 \%),{ }^{2}$ and the absence of the eye and cardiovascular abnormalities typical of Marfan's syndrome. Since then, however, serious eye and cardiac abnormalities that lessen the distinction from Marfan's syndrome have been described. ${ }^{3-5}$ 
We report a case of congenital contractural arachnodactyly complicated by iridodonesis (shimmering iris) and anterior megalophthalmos (enlarged anterior segment).

\section{Case report}

An infant girl was delivered normally at term after an uneventful pregnancy with normal liquor volume. She was the fourth child of healthy 25 year old unrelated parents and the other siblings (age 8,5, and 4 years) were normal. Her birth weight was $3750 \mathrm{~g}$ ( $>50$ th and $<75$ th percentile) and length was $57 \mathrm{~cm} \mathrm{(3}$ cm $>97$ th percentile). She had gross arachnodactyly (fig 1), dolichostenomelia, prominent symmetrical flexion contractures of the knees, hips, elbows, and ankles, and appreciable enophthalmos. The ears were unremarkable. A loud pansystolic murmur and click were present and cardiac ultrasound demonstrated mitral and tricuspid regurgitation; skeletal survey showed arachnodactyly. Chromosome studies and urinary homocystine concentrations were normal.

From the age of 6 weeks she required diuretic treatment for cardiac failure. There was failure to thrive, but her developmental milestones were not significantly delayed. She was noted to have iridodonesis. Ophthalmic examination at this time and at 4 months confirmed iridodonesis in association with anterior megalophthalmos, alternating divergent squint (fig 2), myopic astigmatism, normal fundoscopy, and no evidence of lens subluxation on slit lamp biomicroscopy. She fixed and followed objects with each eye.

There was a gradual spontaneous improvement in all her joint contractures with time. Hospital admissions with persisting vomiting or

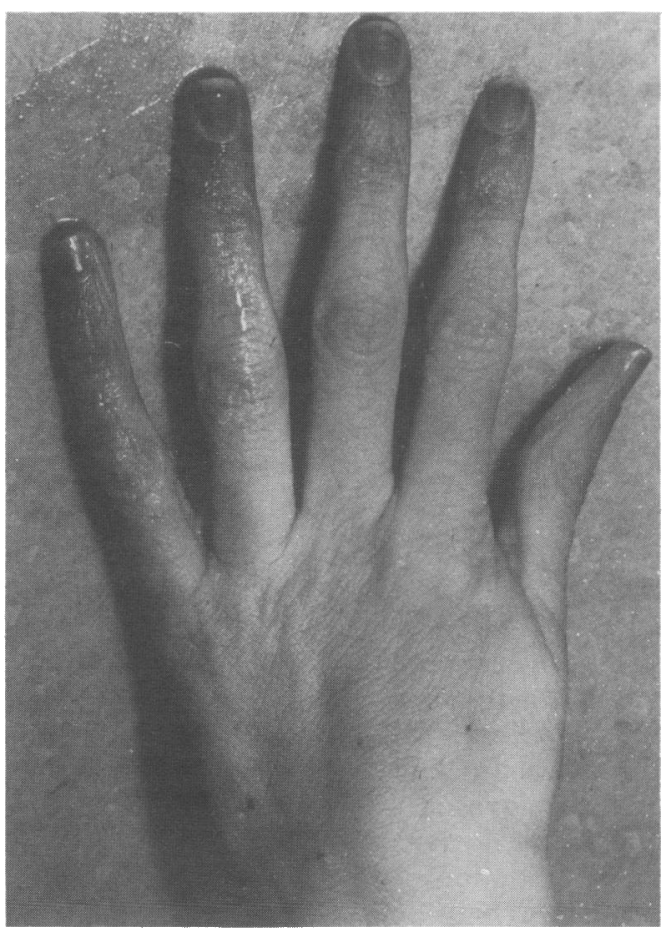

Figure 1 Hand showing gross arachnodactyly.



Figure 2 Infant with enophthalmos, alternating divergent squint, and megalocornea at 3 months of age.

exacerbations of cardiac failure were frequent and she died aged 4 months.

Permission for necropsy was limited to examination of the heart. This confirmed incompetence of the mitral and tricuspid valves. The chordae tendineae attached to the posterior leaflet of the mitral value had ruptured permitting prolapse into the left atrium, which was thought to be the immediate cause of death.

\section{Discussion}

The condition of this 4 month old infant with resolving congenital contractures, arachnodactyly, fatal mitral regurgitation, and iridonesis presumably arose as a spontaneous mutation. In the original description of congenital contractural arachnodactyly the authors argued that the absence of severe cardiac and ophthalmic abnormalities helped to distinguish congenital contractural arachnodactyly from Marfan's syndrome and indicated a better prognosis in the former. ${ }^{1}$ Subsequent reports of congenital contractural arachnodactyly in patients with mitral valve prolapse ${ }^{5}$ and regurgitation, ${ }^{4}$ keratoconus, ${ }^{3}$ and myopia ${ }^{5}$ have blurred this distinction. The presence of congenital symmetrical contractures at birth maximally involving the knees and enophthalmos, as in our case, favours the diagnosis of congenital contractural arachnodactyly.

The concept that congenital contractural arachnodactyly and Marfan's syndrome are separate entities is challenged by the kindred described by Bass et al, where one family member appeared to satisfy better the criteria for Marfan's syndrome while the remainder had congenital contractural arachnodactyly. ${ }^{3}$ Until specific biochemical or genetic abnormalities, 
or both, are identified that differentiate these syndromes their separate existence based on clinical criteria alone will be disputed by some.

Before this report, iridodonesis, which is usually associated with lens subluxation, has only been described in cases with Marfan's syndrome. The iridodonesis in our patient appeared secondary to anterior megalophthalmos, rather than to isolated lens subluxation. Anterior megalophthalmos has occurred rarely in Marfan's syndrome, ${ }^{6}$ but has not been previously described in congenital contractural arachnodactyly. Slit lamp biomicroscopy is helpful in distinguishing these abnormalities.

Although patients with congenital contractural arachnodactyly are less likely than those with Marfan's syndrome to develop serious ocular and cardiovascular complications, the case we describe emphasises the importance of serial cardiovascular and ophthalmic assessment of all these patients and further blurs their clinical separation.

We wish to thank Dr B A M Smith for permitting us to write this report on his patient.

1 Beals RK, Hecht F. Contractural arachnodactyly, a heritable disorder of connective tissue. $\mathcal{F}$ Bone foint Surg [Am] 1971;53:987-93.

2 Ramos Arroya MA, Weaver DD, Beals RK. Congenita contractural arachnodactyly: report of four additiona families and review of the literature. Clin Genet 1985;27 570-81.

3 Bass HN, Sparkes RS, Crandall BF, Marcy SM. Congenital contractural arachnodactyly, keratoconus and probable Marfan syndrome in the same pedigree. $\mathcal{F}$ Pediatr 1981;98: 591-3.

4 Gruber MA, Graham TP, Engel E, Smith C. Marfan syndrome with contractural arachnodactyly and severe syndrome with contractural arachnodactyly and severe
mitral regurgitation in a premature infant. $\mathcal{f}$ Pediatr

5 Anderson RA, Koch S, Camerini-Otero RD. Cardiovascular findings in congenital contractural arachnodactyly: repor of an affected kindred. Am $\mathcal{F}$ Med Genet 1984;18:265-71.

6 Duke Elder S, ed. Normal and abnormal development. Part 2, congenital deformities. System of ophthalmology. Vol 3. London: Kimpton, 1963:501. 